\title{
Avoiding misdiagnosis: expert consensus recommendations for the suspicion and diagnosis of transthyretin amyloidosis for the general practitioner
}

Morie Gertz ${ }^{1 *}$ (D), David Adams², Yukio Ando ${ }^{3}$, João Melo Beirão ${ }^{4}$, Sabahat Bokhari ${ }^{5}$, Teresa Coelho ${ }^{6}$, Raymond L. Comenzo ${ }^{7}$, Thibaud Damy ${ }^{8}$, Sharmila Dorbala ${ }^{9}$, Brian M. Drachman ${ }^{10}$, Marianna Fontana ${ }^{11}$, Julian D. Gillmore ${ }^{11}$, Martha Grogan ${ }^{1}$, Philip N. Hawkins' ${ }^{11}$, Isabelle Lousada ${ }^{12}$, Arnt V. Kristen ${ }^{13}$, Frederick L. Ruberg ${ }^{14}$, Ole B. Suhr ${ }^{15}$, Mathew S. Maurer ${ }^{5}$, Jose Nativi-Nicolau ${ }^{16}$, Candida Cristina Quarta ${ }^{11}$, Claudio Rapezzi ${ }^{17}$, Ronald Witteles ${ }^{18}$ and Giampaolo Merlini ${ }^{19,20}$

\begin{abstract}
Background: Transthyretin amyloidosis (also known as ATTR amyloidosis) is a systemic, life-threatening disease characterized by transthyretin (TTR) fibril deposition in organs and tissue. A definitive diagnosis of ATTR amyloidosis is often a challenge, in large part because of its heterogeneous presentation. Although ATTR amyloidosis was previously considered untreatable, disease-modifying therapies for the treatment of this disease have recently become available. This article aims to raise awareness of the initial symptoms of ATTR amyloidosis among general practitioners to facilitate identification of a patient with suspicious signs and symptoms.
\end{abstract}

Methods: These consensus recommendations for the suspicion and diagnosis of ATTR amyloidosis were developed through a series of development and review cycles by an international working group comprising key amyloidosis specialists. This working group met to discuss the barriers to early and accurate diagnosis of ATTR amyloidosis and develop a consensus recommendation through a thorough search of the literature performed using PubMed Central.

Results: The cardiac and peripheral nervous systems are most frequently involved in ATTR amyloidosis; however, many patients often also experience gastrointestinal and other systemic manifestations. Given the multisystemic nature of symptoms, ATTR amyloidosis is often misdiagnosed as a more common disorder, leading to significant delays in the initiation of treatment. Although histologic evaluation has been the gold standard to confirm ATTR amyloidosis, a range of tools are available that can facilitate early and accurate diagnosis. Of importance, genetic testing should be considered early in the evaluation of a patient with unexplained peripheral neuropathy.

(Continued on next page)

\footnotetext{
* Correspondence: gertz.morie@mayo.edu

${ }^{1}$ Mayo Clinic, 200 First Street SW, Rochester, MN 55905, USA

Full list of author information is available at the end of the article
}

(c) The Author(s). 2020 Open Access This article is licensed under a Creative Commons Attribution 4.0 International License, which permits use, sharing, adaptation, distribution and reproduction in any medium or format, as long as you give appropriate credit to the original author(s) and the source, provide a link to the Creative Commons licence, and indicate if changes were made. The images or other third party material in this article are included in the article's Creative Commons licence, unless indicated otherwise in a credit line to the material. If material is not included in the article's Creative Commons licence and your intended use is not permitted by statutory regulation or exceeds the permitted use, you will need to obtain permission directly from the copyright holder. To view a copy of this licence, visit http://creativecommons.org/licenses/by/4.0/. The Creative Commons Public Domain Dedication waiver (http://creativecommons.org/publicdomain/zero/1.0/) applies to the data made available in this article, unless otherwise stated in a credit line to the data. 
(Continued from previous page)

Conclusions: A diagnostic algorithm based on initial red flag symptoms and manifestations of cardiac or neurologic involvement will facilitate identification by the general practitioner of a patient with clinically suspicious symptoms, enabling subsequent referral of the patient to a multidisciplinary specialized medical center.

Keywords: ATTR amyloidosis, ATTRv, Diagnosis, hATTR, Polyneuropathy, Cardiomyopathy, Transthyretin amyloidosis

\section{Background}

Transthyretin amyloidosis (also known as ATTR amyloidosis) is a devastating, life-threatening, and underrecognized disease wherein misfolded transthyretin (TTR) protein forms fibrils and deposits in organs and tissue, disrupting normal organ function and tissue structure [1-3]. Under homeostatic conditions, tetrameric TTR complexes transport thyroid hormone and retinol binding protein $[4,5]$. With ATTR amyloidosis, amyloid fibril formation occurs because of a single amino acid substitution or complex instability, causing tetrameric TTR to dissociate into monomers, which misfold and aggregate before depositing into tissue and organs $[4,6]$. Accumulation of TTR amyloid fibrils results in multisystem dysfunction with clinical manifestations observed in the heart, musculoskeletal system, peripheral nervous system, and autonomic nervous system. ATTR amyloidosis is a progressive and systemic disease and may be either hereditary (ATTRv; $v$ for variant) or sporadic (ATTRwt; wt for wild type) [7]. ATTRv and ATTRwt amyloidosis can result in a heterogeneous, multisystem presentation of clinical manifestations in patients with life expectancy depending on several factors, such as the form of disease, age, predominant phenotype, comorbidities, and duration of symptoms before diagnosis (Table 1). Although ATTR amyloidosis was previously untreatable, the landscape changed quickly in 2018 to 2019 with the US Food and Drug
Administration approval of three new, effective diseasemodifying therapies for the treatment of ATTRv-related peripheral neuropathy (ATTRv-PN) and ATTRv or ATTRwt-related cardiomyopathy (ATTRv-CM or ATTRwt-CM, respectively) [29-31].

The prevalence of ATTR amyloidosis is higher than previously recognized. An autopsy study found that ATTRwt may be present in as many as $25 \%$ of persons older than 80 years [32], whereas a separate autopsy study noted that ATTRwt may be the cause of heart failure (HF) in 5\% of patients with HF with preserved ejection fraction (HFpEF) [33]. Nuclear scintigraphy has suggested that $13 \%$ of patients admitted to the hospital with HFpEF and as many as $16 \%$ of elderly patients with severe degenerative aortic stenosis may have ATTRwt$\mathrm{CM}[34,35]$. One genetic variant, V122I, is carried by $3.4 \%$ of African Americans. This means that approximately 1.5 million people (out of 50 million total African Americans in 2018) are carriers of and are therefore at elevated risk for cardiac amyloidosis [36-40]. The genetic variants causing ATTRv follow an autosomal dominant pattern; consequently, ATTRv has typically been considered an endemic disease with an early onset and is prevalent in endemic regions (such as Japan, Sweden, and Portugal) [16, 41]. However, penetrance is variable and has not been assessed for many variants [42]. ATTRv-PN is now considered to be a worldwide disease, with a global prevalence estimated at 10,186 cases [43].

Table 1 Clinical manifestations of ATTRV and ATTRwt amyloidosis

\begin{tabular}{|c|c|c|c|}
\hline & ATTRV & ATTRwt & References \\
\hline Age at symptom onset & $>20$ years & $>50$ years & {$[8-12]$} \\
\hline Male, \% & $76-86$ & $91-97$ & [13-15] \\
\hline Duration of symptoms before diagnosis & $\sim 3$ years & $\sim 2$ years & {$[8,9,11]$} \\
\hline Median life expectancy, after diagnosis & $\begin{array}{l}\cdot 2-5 \text { years with predominantly CM } \\
\cdot \text { - }-10 \text { years with predominantly PN }\end{array}$ & 4 years & {$[9,12,16,17]$} \\
\hline \multicolumn{4}{|l|}{ Clinical manifestation } \\
\hline Cardiac & Yes & Yes & {$[13,18,19]$} \\
\hline Peripheral nerves & Yes & Occasionally & {$[13,18]$} \\
\hline Autonomic nerves (including gastrointestinal) & Yes & Rare & {$[13,18,20,21]$} \\
\hline Kidney & Yes & Rare & {$[1,13]$} \\
\hline Ophthalmologic & Vitreous deposition & Not prominent & {$[1]$} \\
\hline Musculoskeletal & Yes & Yes & {$[13,22-28]$} \\
\hline
\end{tabular}

ATTRv Hereditary ATTR amyloidosis, ATTRwt Wild-type ATTR amyloidosis, CM Cardiomyopathy, PN Polyneuropathy 
The aim of this article is to heighten disease awareness, to increase clinical suspicion in the presence of signs and symptoms suggestive of ATTR amyloidosis, and to promote proper testing and referrals among general practitioners, who are typically the first point of contact for a newly symptomatic patient. Moreover, symptoms are often heterogeneous and can be incorrectly associated with a more common disorder.

\section{Methods}

These consensus recommendations for the suspicion and diagnosis of hereditary and wild-type ATTR amyloidosis were developed through a series of development and review cycles through in-person meetings, along with refinement of the draft by telephone or email. The Amyloidosis Research Consortium has created a collaborative research model to bring together experts in the amyloidosis field to address the challenges that exist in developing diagnostic tools and carrying out innovative clinical trials. An international working group composed of key amyloidosis specialists in collaboration with companies conducting research in ATTR amyloidosis (GlaxoSmithKline, Ionis, Pfizer, and Alnylam) and the Amyloidosis Research Consortium was assembled. The international working group met to discuss challenges to early and accurate diagnosis of ATTR amyloidosis and to develop a consensus recommendation for the diagnosis of ATTR amyloidosis, recognizing that whether a patient presents in an endemic or a non-endemic country and has early or late-onset disease will influence the patient pathway to diagnosis. An initial thorough search of the literature was performed using PubMed Central and the following search terms: (amyloid OR amyloidosis) AND transthyretin OR (senile or SSA or SCA or TTR or ATTR or cardiac or FAP or FAC or mutant or hereditary or familial or neuropathy or ATTRv or mATTR or hATTR or wtATTR). The results of this broad and expansive search were further refined focusing on references concerning suspicion of disease and diagnosis, and the resultant list was consequently reviewed by the working group. Although only one database was searched, the initial search was exhaustive and the review by the authors, who are global experts in the field, ensured that all the appropriate references were identified. Several publications have sought to provide clinical guidelines for the diagnosis and management of ATTR amyloidosis [1, 16, 41, 44, 45]. Five clinical practice guidelines were analyzed to assess similarities and differences between them [1, 16, 41, 44, 45]; these findings were incorporated, along with the results of the literature search and the medical expertise of the international working group, to develop the final consensus recommendations.

\section{Results}

\section{Underrecognition}

Although prevalence is higher than previously recognized, ATTR amyloidosis remains a challenging disease to identify largely because it manifests with varied symptoms and may involve multiple organs (Fig. 1a) [1]. Symptoms often mimic those of other more common diseases, rendering accurate diagnosis of ATTR amyloidosis difficult [46, 47]. In a survey of patients with ATTR amyloidosis, diagnosis was made within 6 months in only 35\% of those with ATTRv and $46 \%$ of those with ATTRwt, with many patients seeing more than five physicians before receiving a correct diagnosis (Fig. 1b) [46, 47].

The cardiac and peripheral nervous systems are most commonly involved in patients with ATTR amyloidosis. ATTR-CM (transthyretin amyloid cardiomyopathy) typically causes heart failure and/or arrhythmias, whereas neurologic involvement is characterized by a progressive peripheral and autonomic neuropathy that can rapidly become severe and disabling. Early identification and intervention are crucial to improve patient outcomes because newly available treatments have been shown to have maximum therapeutic benefit when started in the early stages of the disease.

In recent years, contemporary cardiac imaging techniques, including magnetic resonance imaging (MRI) and bone scintigraphy, have dramatically altered the diagnostic algorithm for ATTR-CM, which has resulted in increased detection, demonstrated by an increase in patient referrals to the National Amyloidosis Centre in London in the United Kingdom since 2012 [47]. These referred patients, however, have still routinely presented with advanced HF and poor quality of life [47]. In addition to increasing disease awareness among physicians, screening algorithms that capture patients with known ATTR variants or family members of patients with known disease can help identify affected but clinically unrecognized individuals. In addition, emerging data indicate that ATTR-CM screening should be considered for older adults with bilateral carpal tunnel syndrome (CTS) [22], spinal stenosis [23, 48], HFpEF, and/or a hypertrophic cardiomyopathy phenotype to improve disease detection and diagnosis [34]. Earlier diagnosis is crucial for all patients irrespective of genotype, and, given the inherited nature of ATTRv, diagnosis of one patient with ATTRv has important ramifications for all first-degree relatives, who may then be monitored and treated as soon as symptoms arise [49].

\section{Burden of disease}

The burden of disease is high for patients and caregivers. Patients who completed the 36-Item Short Form Health Survey (SF-36) reported scores up to 2 standard deviations below those seen in the general population for physical 
a.

\begin{tabular}{|c|c|}
\hline $\begin{array}{l}\text { OCULAR } \\
\text { MANIFESTATIONS } \\
\text { - Dark Floaters } \\
\text { - Glaucoma } \\
\text { - Abnormal blood vessels in eye } \\
\text { - Pupillary abnormalities } \\
\text { - Dry eye }\end{array}$ & $\begin{array}{l}\text { CARDIOVASCULAR } \\
\text { MANIFESTATIONS } \\
\text { - Irregular heart beat } \\
\text { - Conduction blocks } \\
\text { - Congestive heart failure (including } \\
\text { shortness of breath, generalized } \\
\text { fatigue, peripheral edema) } \\
\text { - Ventricular wall thickening with } \\
\text { preserved ejection fraction and } \\
\text { absence of left ventricular dilation }\end{array}$ \\
\hline $\begin{array}{l}\text { NEPHROPATHY } \\
\text { - Protein in urine } \\
\text { - Renal failure } \\
\text { BILATERAL CARPAL } \\
\text { TUNNEL SYNDROME } \\
\text { - Numbness and tingling in the } \\
\text { hands and arms }\end{array}$ & $\begin{array}{l}\text { AUTONOMIC } \\
\text { NEUROPATHY } \\
\text { - Orthostatic hypotension } \\
\text { - Recurrent urinary tract infections } \\
\text { (due to urinary retention) } \\
\text { - Sexual dysfunction } \\
\text { - Sweating abnormalities } \\
\text { - Nausea and vomiting }\end{array}$ \\
\hline $\begin{array}{l}\text { PERIPHERAL } \\
\text { SENSORIMOTOR } \\
\text { NEUROPATHY } \\
\text { - Weakness, numbness, or pain } \\
\text { beginning in the hands and feet } \\
\text { that can progress to the central } \\
\text { part of the body } \\
\text { - Gait disability } \\
\text { - Balance disorder }\end{array}$ & $\begin{array}{l}\text { GASTROINTESTINAL } \\
\text { MANIFESTATIONS } \\
\text { - Nausea and vomiting } \\
\text { - Early satiety } \\
\text { - Diarrhea } \\
\text { - Constipation } \\
\text { - Diarrhea/constipation } \\
\text { - Unintentional weight loss }\end{array}$ \\
\hline
\end{tabular}

b. Number of physicians seen before patient received a correct diagnosis

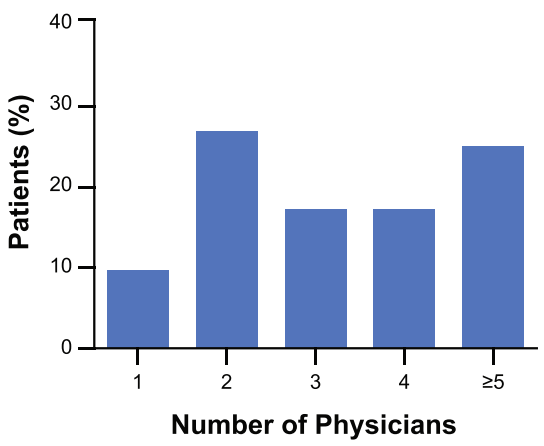

Fig. 1 Systemic manifestations of ATTR amyloidosis commonly result in delayed diagnosis. a The varied systemic manifestations of ATTR amyloidosis. Modified with permission from Conceição I, et al. [1]. b The number of physicians seen before a patient is correctly diagnosed. Adapted with permission from Lousada L, et al. [46]. ATTR, transthyretin amyloid

health, quality of life, and work productivity. Neuropathyspecific quality of life for patients with ATTRv, as measured with the Norfolk QOL-Diabetic Neuropathy questionnaire, was nearly equivalent to that of patients with type 2 diabetes with diabetic neuropathy accompanied by a history of ulceration, gangrene, or amputation. Generic quality of life, as measured with the SF-36, was worse than that seen in the general population, and physical functioning was worse than that for patients with multiple sclerosis and congestive HF [50]. Caregivers also report poor mental health, poor work productivity, and a considerable amount of time required to provide care (mean, $45.9 \mathrm{~h} /$ week) [51]. It has also been shown that patient quality of life is poor at the time of diagnosis, indicating that substantial ATTR amyloidosis disease progression has often occurred before that time [47]. 


\section{Discussion}

The diagnostic process leading to the final diagnosis of ATTR amyloidosis can be framed in two distinct (albeit interconnected) phases: clinical suspicion and diagnosis. Both phases have many pitfalls, and the steps involved can be challenging.

\section{Clinical suspicion of cardiac involvement: presenting symptoms and common misdiagnoses}

The most common presenting signs and symptoms of ATTR-CM are orthopnea, paroxysmal nocturnal dyspnea, fatigue, exercise intolerance, dizziness/syncope, palpitations, atrial fibrillation, thromboembolism, and fluid retention [13, 34, 52-55]. Cardiac symptoms are sometimes accompanied by other systemic manifestations, such as unexplained peripheral neuropathy, or gastrointestinal (GI) symptoms, such as early satiety, nausea, vomiting, and/or altered bowel habits [20]. A history of surgically corrected bilateral CTS and/or lumbar stenosis is a red flag and should prompt consideration of ATTR amyloidosis because these symptoms can be early manifestations of the disease (ATTRwt and ATTRv) [22-27].

Echocardiographic (ECHO) findings of ATTR amyloidosis can often lead to a misdiagnosis of hypertrophic cardiomyopathy; in older adults, ATTR amyloidosis is the most common phenocopy for hypertrophic cardiomyopathy [56]. Hypertensive cardiac remodeling and undifferentiated HFpEF are also common misdiagnoses (Table 2) [34].

Further signs of amyloidosis are seen on ECHO or cardiac magnetic resonance (CMR) imaging; specifically, left ventricular walls are nearly invariably thickened, and coexisting pericardial effusion, right ventricular wall thickening, and interatrial septal thickening are often seen [57]. Another important finding is a disproportion between left ventricular wall thickness and QRS voltages [58, 59]. Readily available tests that can assist in raising the index of clinical suspicion include $\mathrm{ECHO}$, electrocardiography (ECG), CMR with late gadolinium enhancement/extracellular volume, or bone scintigraphy (technetium-99 m-labeled pyrophosphate [PYP], 3,3-diphosphono-1,2propanodicarboxylic acid [DPD], hydroxymethylene

Table 2 Common Misdiagnoses of Disturbances Caused by ATTR Amyloidosis

\begin{tabular}{|c|c|}
\hline Common Misdiagnosis & ATTR Symptoms Contradicting Given Diagnosis \\
\hline \multicolumn{2}{|l|}{ Cardiac } \\
\hline Hypertrophic cardiomyopathy & Discordant voltage to mass ratio \\
\hline Hypertensive heart disease & $\begin{array}{l}\text { Discordant voltage to mass ratio; intolerance to beta blockers; waning need for } \\
\text { antihypertensives }\end{array}$ \\
\hline $\begin{array}{l}\text { Undifferentiated heart failure with preserved ejection } \\
\text { fraction }\end{array}$ & Nondilated hypertrophic LV \\
\hline Uncomplicated degenerative aortic stenosis & $\begin{array}{l}\text { Reduced longitudinal strain } \\
\text { Frequent low-flow, low-gradient paradoxical pattern } \\
\text { Thickened atrioventricular valves }\end{array}$ \\
\hline \multicolumn{2}{|l|}{ Neurologic } \\
\hline Chronic inflammatory demyelinating polyneuropathy & $\begin{array}{l}\text { Pain in the limbs, dysautonomia (erectile dysfunction, } \mathrm{OH} \text { ), symmetric polyneuropathy in } \\
\text { upper limbs }\end{array}$ \\
\hline Idiopathic axonal polyneuropathy & Dysautonomia (erectile dysfunction, $\mathrm{OH}$ ), walking difficulties \\
\hline CTS & Worsening of upper limb symptoms despite CTS surgery \\
\hline Lumbar spinal stenosis & Failure to relieve symptoms in spite of spine surgery \\
\hline Diabetic neuropathy & Walking difficulties \\
\hline Amyotrophic lateral sclerosis & $\begin{array}{l}\text { No upper motor neuron syndrome } \\
\text { Reduction of amplitude of SNAP }\end{array}$ \\
\hline Motor neuropathy & Reduction of amplitude of SNAP \\
\hline
\end{tabular}

\section{Gastrointestinal}

Inflammatory bowel syndrome

Irritable bowel syndrome

Idiopathic diarrhea

Idiopathic bile acid malabsorption

Pseudo-obstruction
Absence of inflammation

Absence of or only minor abdominal pain; weight loss

Weight loss

Absence of or only minor abdominal pain or radiologic findings of intestinal obstruction

ATTR Transthyretin amyloidosis, CTS Carpal tunnel syndrome, Gl Gastrointestinal, LV Left ventricle, OH Orthostatic hypotension, SNAP Sensory nerve action potential 
diphosphonate [HMDP]) (Fig. 2, Table 3) [53, 60-64]. Use of serum cardiac biomarkers such as troponin levels, $\mathrm{N}$ terminal probrain natriuretic peptide plasma levels, and free light chain/serum and urine immunofixation electrophoresis to exclude light-chain amyloidosis (AL) are also diagnostically useful $[53,63,64]$.

\section{Clinical suspicion of neural involvement: presenting symptoms and common misdiagnoses}

The wide spectrum of clinical presentation and inaugural manifestations makes amyloid neuropathy a "chameleon-like" neuropathy; consequently, early diagnosis of ATTRv-PN can be challenging for general

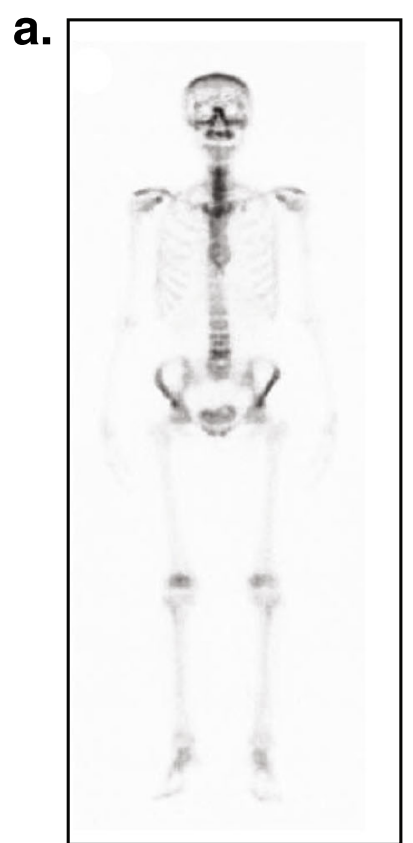

b.

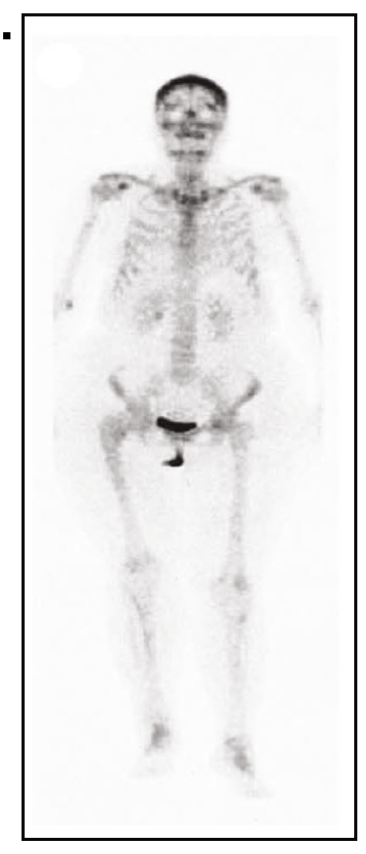

C.

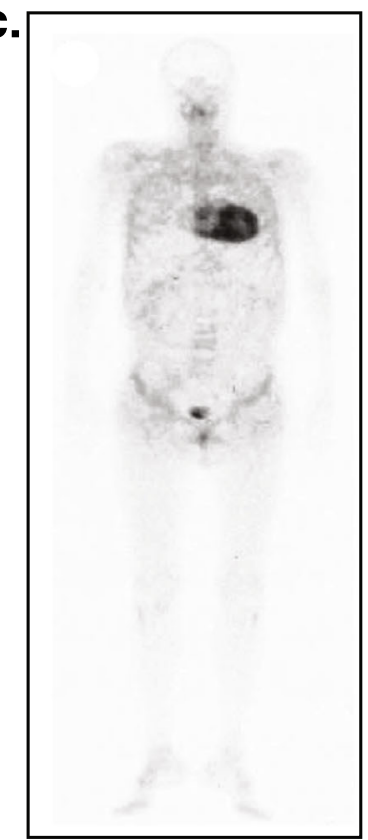

d.

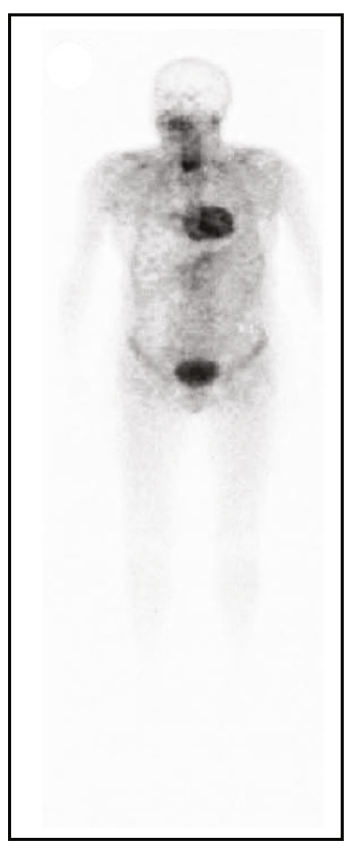

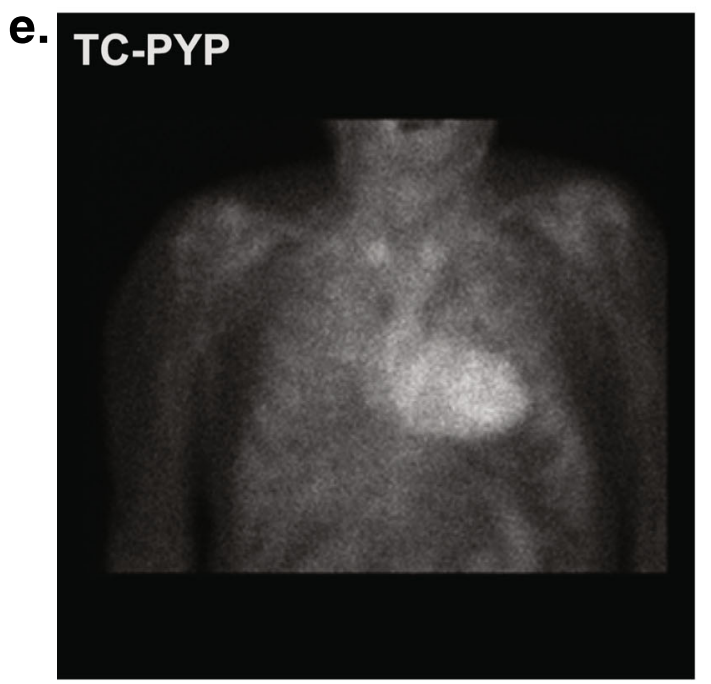

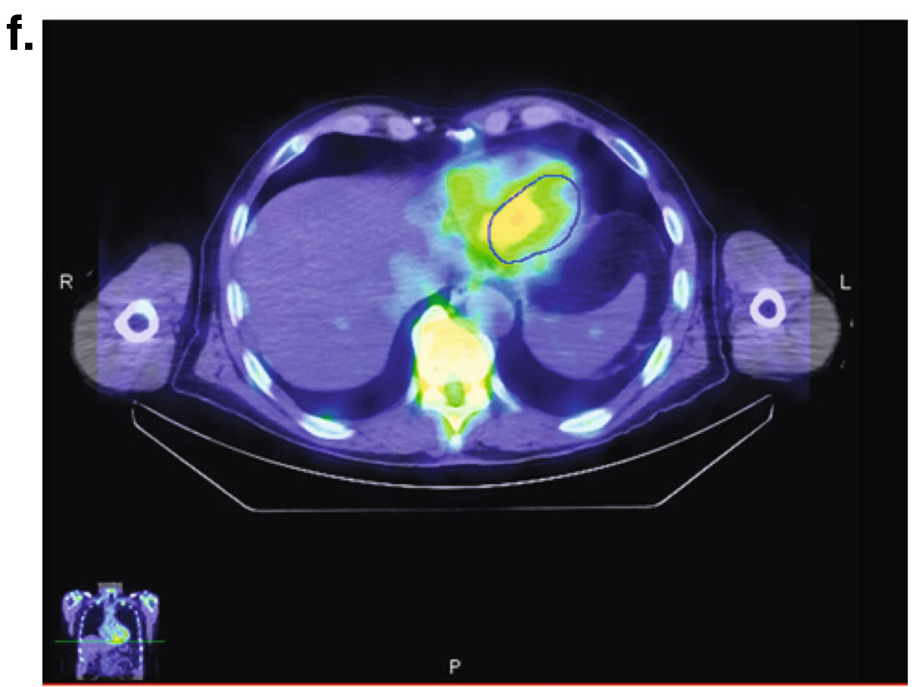

Fig. 2 Assessments for noninvasive diagnosis of ATTR amyloidosis. (A-D) ${ }^{99}{ }^{9} T c-D P D$ bone tracer scintigraphy. a No uptake outside of bone (score 0 ) is typical of patients without ATTR amyloidosis. b Some uptake outside of bone without myocardial uptake (score 1) may be seen in AL amyloidosis or possibly ATTR amyloidosis; if suspicion is high, consider a biopsy. c Moderate (score 2, myocardial uptake = rib uptake) and $\mathbf{d}$ high (score 3, myocardial uptake > rib uptake) uptake in the heart along with suspicious symptoms is diagnostic for ATR amyloidosis (serum and urine immunofixation and FLC levels must be normal to discount AL amyloidosis). e, $\mathbf{f}^{99 m}$ Tc-PYP bone tracer scintigraphy. e Planar chest and $\mathbf{f}$ SPECT chest scans that demonstrate uptake both in blood pool and in the myocardial wall. ${ }^{99 m}$ Tc-DPD, technetium-99 m-3,3-diphosphono-1,2 propanodicarboxylic acid; ${ }^{99 \mathrm{~m}} \mathrm{TC}$-PYP, technetium-99 m pyrophosphate; AL, light-chain amyloidosis; ATTR, transthyretin amyloid; FLC, free light chain; SPECT, single photon emission computed tomography. a-d Reused with permission from Perugini E, et al. [60]. e-f Courtesy of Morie Gertz 
Table 3 Clinical Tests and Findings Potentially Suggestive of ATTR Amyloidosis

\begin{tabular}{|c|c|}
\hline \multicolumn{2}{|l|}{ Heart } \\
\hline ECG & $\begin{array}{l}\text { Normal or low ECG voltage }{ }^{a} \text { often } \\
\text { discrepant from ECHO findings, pseudo- } \\
\text { infarct pattern, atrioventricular block, bun- } \\
\text { dle branch block }\end{array}$ \\
\hline $\mathrm{ECHO}$ & $\begin{array}{l}\text { Increased left and/or right ventricular wall } \\
\text { thickness, increased atrial septal thickness, } \\
\text { impaired longitudinal strain, apical sparing } \\
\text { pattern by longitudinal strain, thickened } \\
\text { valve leaflets, increased LV filling pressures, } \\
\text { pericardial effusion }\end{array}$ \\
\hline CMR & $\begin{array}{l}\text { Increased biventricular wall thickness, } \\
\text { increased LV mass, diffuse subendocardial } \\
\text { or transmural late gadolinium } \\
\text { enhancement, increased native noncontrast } \\
\text { T1 and ECV }\end{array}$ \\
\hline $\begin{array}{l}{ }^{99 m} \mathrm{Tc} \text { bone scintigraphy } \\
\text { (DPD/PYP/HMDP) }\end{array}$ & $\begin{array}{l}\text { Grade } 2 / 3 \text { myocardial uptake; note, this test } \\
\text { should always be ordered with serum FLC/ } \\
\text { serum and urine immunofixation } \\
\text { electrophoresis to rule out the presence of } \\
\text { a monoclonal protein. If any of these are } \\
\text { abnormal, endomyocardial biopsy with } \\
\text { typing of amyloid fibril may be necessary } \\
\text { for an accurate diagnosis }\end{array}$ \\
\hline $\begin{array}{l}\text { Serum cardiac } \\
\text { biomarkers }\end{array}$ & $\begin{array}{l}\text { Increased BNP or NT-proBNP levels, in- } \\
\text { creased troponin T or troponin I levels }\end{array}$ \\
\hline \multicolumn{2}{|l|}{ Peripheral nerves } \\
\hline Nerve conduction study & Axonal sensorimotor neuropathy, CTS \\
\hline Neuro MRI & Swelling of dorsal ganglia \\
\hline \multicolumn{2}{|l|}{ Autonomic nerves } \\
\hline Schellong test & Neurologic orthostatic hypotension \\
\hline CVRR & Decreased CVRR \\
\hline $\begin{array}{l}\text { Sweat test } \\
\text { Laser Doppler flowmetry }\end{array}$ & Anhidrosis, hypohidrosis \\
\hline
\end{tabular}

ATTR Transthyretin amyloid, ATTRwt Wild-type transthyretin amyloidosis, BNP Brain natriuretic peptide, $C M R$ Cardiovascular magnetic resonance, $C T$ Computed tomography, CTS Carpal tunnel syndrome, CVRR Coefficient of variation in electrocardiographic R-R interval variability, DPD 3,3-diphosphono1,2-propanodicarboxylic acid, ECG Electrocardiography, ECHO Echocardiography, ECV Extracellular volume, FLC Free light chain, HMDP Hydroxymethylene diphosphonate, $L V$ Left ventricular, LVWT Left ventricular wall thickness, MR Magnetic resonance, MRI Magnetic resonance imaging, NTproBNP N-terminal probrain natriuretic peptide, PYP Pyrophosphate, $\pi R$ Transthyretin

${ }^{a}$ Criteria for low voltage is present in only $25 \%$ of patients with ATTRwt; most patients, however, will have a low "voltage to mass" ratio

practitioners and specialists. The most common presenting symptoms of neurologic involvement include progressive sensory polyneuropathy, autonomic dysfunction (eg, chronic or alternating diarrhea and/or constipation, erectile dysfunction, and postural hypotension), pain in the hands or feet, and gait disorders [1, 14, 16, 65, 66]. Patients often present with other systemic signs, such as unexplained weight loss, cardiac symptoms (as already described), ocular manifestations, or renal abnormalities. Neurologic involvement frequently precedes the appearance of cardiac involvement by more than 5 years and often indicates that the disease is genetic in origin (ATTRv). CTS may be a particularly early sign for certain variants of ATTRv (eg, T60A) [66, 67].

Misdiagnoses of ATTR amyloidosis with neuropathy commonly include chronic inflammatory demyelinating polyradiculoneuropathy (CIDP), idiopathic axonal polyneuropathy, lumbar spinal stenosis, diabetic neuropathy, CTS, paraneoplastic neuropathy, monoclonal gammopathy-associated neuropathy, and, more rarely, motor neuropathy, inherited neuropathy, and amyotrophic lateral sclerosis (Table 2) [23, 65, 68-70].

\section{Clinical suspicion of gastrointestinal involvement: presenting symptoms and common misdiagnoses}

The most common presenting symptoms of amyloidrelated GI disturbances include chronic diarrhea or diarrhea alternating with constipation, unintentional weight loss often associated with early satiety, and a typical absence of abdominal pain [13, 20]. It is not uncommon for ATTRv to manifest first in the GI tract; therefore, the absence of peripheral neuropathy should not preclude clinical suspicion [71]. When patients present with nausea, vomiting, diarrhea, and weight loss, recognizing other impaired organs can be useful in leading to identification of a systemic disorder. Nephrotic-range proteinuria and cardiomyopathy are ancillary clues that the GI symptoms are amyloid in origin. Patients are often misdiagnosed with irritable bowel syndrome (IBS), unexplained malabsorption syndrome, protein-losing enteropathy secondary to ischemia, celiac disease, or infection. Absence of abdominal pain with a diagnosis of IBS may indicate amyloidosis (Table 2). Unfortunately, there are no specific findings for ATTR enteropathy on routine GI examination (ie, abdominal x-ray, computed tomography, colonoscopy/esophago-gastroduodenoscopy [OGD]) [72]; however, if a biopsy specimen from the GI tract contains the mucosal muscle layer and submucosa, amyloid can be detected with the use of Congo red staining. In addition, gastric retention observed during OGD and coexisting autonomic dysfunction should increase suspicion [73-75].

\section{Diagnosis}

Although histologic documentation of amyloid remains the gold standard for diagnosis, a patient who exhibits any of the presenting signs or symptoms or who has received a diagnosis that appears inconsistent with the overall signs and symptoms should be referred to the appropriate specialist (Figs. 1, 3). Evaluations should include ECHO and/or CMR imaging to identify any thickening of the cardiac walls (as already described) [76]. Symptoms of progressive peripheral neuropathy and/or autonomic dysfunction should prompt a careful evaluation of family history, and a clinical history of CTS 


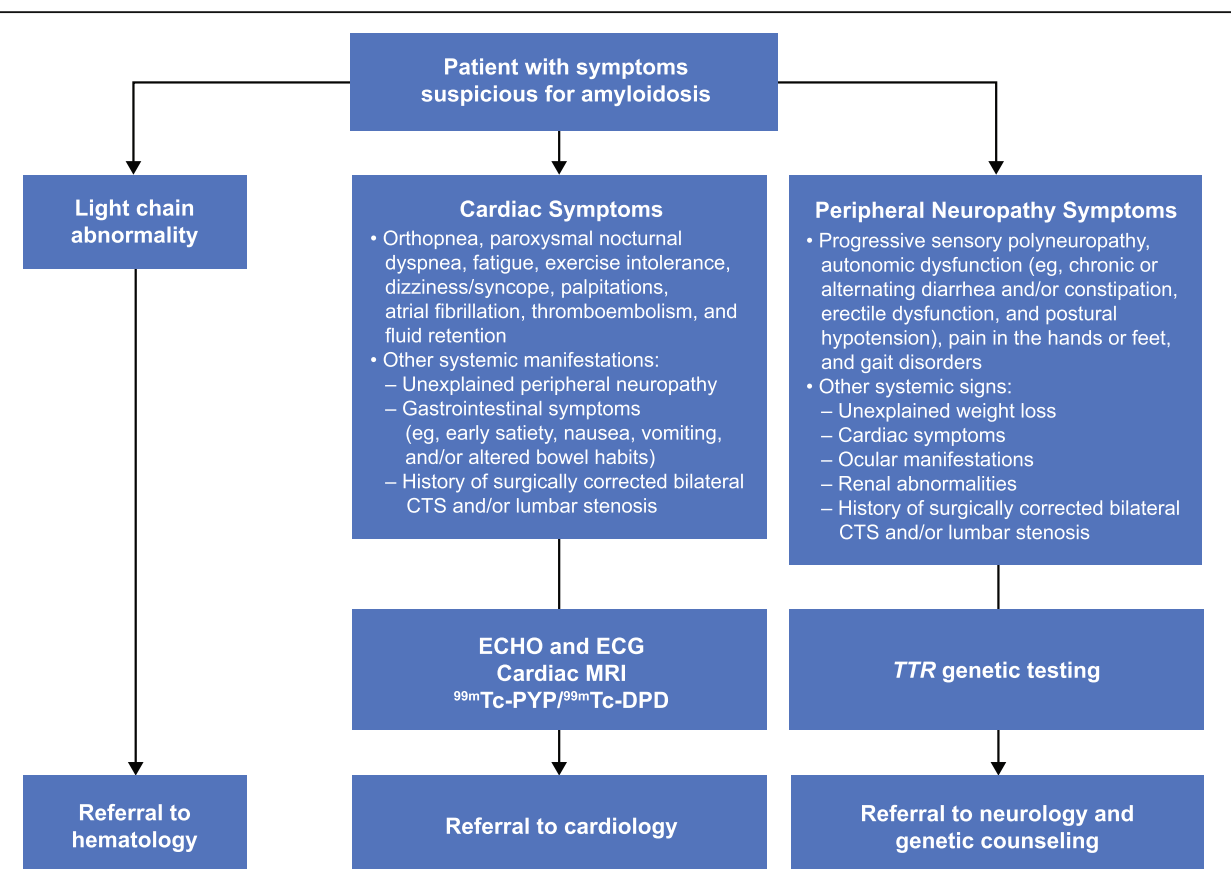

Fig. 3 A general practitioner's algorithm for increased suspicion and diagnosis of ATTR amyloidosis. Schematic of the recommended diagnostic approach for the general practitioner. ${ }^{99 \mathrm{~m}} \mathrm{Tc}$-DPD, technetium-99 m-3,3-diphosphono-1,2 propanodicarboxylic acid; ${ }^{99 \mathrm{~m}} \mathrm{Tc}-\mathrm{PYP}$, technetium-99 m pyrophosphate; ATTR, transthyretin amyloid; MRI, magnetic resonance imaging; TTR, transthyretin

should be elicited [45]. Bone scintigraphy should be performed if serum/urine immunofixation and serum free light chain (FLC) levels are normal; in such cases, bone scintigraphy typically confirms or excludes a diagnosis of ATTR-CM [77, 78]. Bone scintigraphy documenting intense myocardial tracer uptake in the absence of any monoclonal protein in the plasma can be used to make a definitive diagnosis in the case of cardiac and mixed phenotype. If serum/urine immunofixation or FLC levels indicate the presence of a monoclonal immunoglobulin or light chain, a biopsy is required to confirm or exclude the diagnosis. Similarly, if bone scintigraphy is not available or myocardial uptake is mild (score 1), patients should be referred to an experienced center that offers bone scintigraphy or a symptomatic organ should be biopsied for evidence of amyloid and typed by mass spectroscopy or immunostaining [45]. It should be noted that while salivary gland biopsy is comparable to nerve biopsy to confirm a diagnosis, heart biopsy may be preferred in a patient with suspected cardiac involvement $[79,80]$. Nevertheless, there are some potential pitfalls to this diagnostic approach:

a) Tracer uptake can be sparse or absent in patients with definitive cardiomyopathy related to rare mutations (eg, TTR Phe64Leu)

b) When PYP is used as the bone tracer, false-positive myocardial uptake (score 1) at planar images can occur owing to blood pool effect, such that singlephoton emission computerized tomography (SPECT) imaging will be necessary

c) Because grade 2-3 uptake may also be seen in AL amyloidosis, serum and urine immunofixation and FLC levels must be normal for ATTR-CM to be diagnosed using only bone scintigraphy

d) Identification of a monoclonal protein is not diagnostic of AL amyloidosis. Monoclonal gammopathy of undetermined significance can coexist with ATTRwt, especially in elderly patients

e) Interpretation of a biopsy specimen has certain challenges. Indeed, the sensitivity of non-cardiac tissue biopsy (and of abdominal fat biopsy in particular) in patients with ATTRwt is low

In cases of ATTRv with a neurologic phenotype (peripheral neuropathy) and no overt cardiac involvement, evaluations of blood glucose, serum $\mathrm{B}_{12}$ with metabolites (methylmalonic acid with or without homocysteine), and FLC and serum and urine immunofixation electrophoresis should be performed [81]. TTR gene sequencing should be performed in cases of progressive polyneuropathy of seemingly unknown cause accompanied by one of the following red flags: autonomic dysfunction or gastrointestinal disorders, bilateral carpal tunnel syndrome, unexplained weight loss [1, 82], early gait disability [66], or CIDP refractory to intravenous immunoglobulin therapy [1]. If 
one of the 130+ amyloidogenic variants is detected [83], ATTRv polyneuropathy should also be considered and patients referred to a center specializing in neuromuscular diseases.

Once a diagnosis of ATTR amyloidosis has been made, genetic testing by TTR gene sequencing should be performed to establish mutation status. Patients may be referred to an amyloidosis center for further evaluation and treatment. Genetic testing is recommended in all cases of suspected ATTR amyloidosis to aid in diagnosis and to identify whether the disease is hereditary. If the results are positive, family members may choose to see a genetic counselor, be tested themselves, and be monitored for the onset of symptomatic disease [49]. At this phase of the diagnostic workup, the main pitfall of immunohistochemistry is related to the suboptimal specificity of many commercially available antibodies, sometimes leading to simultaneous positivity for ATTR and kappa or lambda light chains. Mass spectrometry is generally able to detect the "leading protein" responsible for the tissue accumulation of amyloid deposits.

\section{Conclusions}

ATTR amyloidosis, a life-threatening and underrecognized disease, was formerly considered untreatable; however, the recent availability of disease-modifying therapies has renewed efforts to increase awareness of the initial disease symptoms and the assessments that are available to confirm a diagnosis. A diagnostic algorithm is recommended for the general practitioner based on initial red flag symptoms and manifestations of cardiac or neurologic involvement, and the early use of genetic testing in patients with unexplained peripheral neuropathy should trigger referral to a multidisciplinary team at an expert center $[1,17,83-87]$.

\footnotetext{
Abbreviations

99m Tc-DPD: Technetium-99 m-3,3-diphosphono-1,2 propanodicarboxylic acid; 99mTc-PYP: Technetium-99 m pyrophosphate; ATTR: Transthyretin amyloid; ATTRV: ATTR variant; ATTR-CM: Transthyretin amyloid cardiomyopathy; ATTRVCM: ATTRv-related cardiomyopathy; ATTRv-PN: ATTRv-related peripheral neuropathy; ATTRwt: Wild-type ATTR; ATTRwt-CM: ATTRwt-related cardiomyopathy; BNP: Brain natriuretic peptide; CIDP: Chronic inflammatory demyelinating polyradiculoneuropathy; CMR: Cardiovascular magnetic resonance; CT: Computed tomography; CTS: Carpal tunnel syndrome; CVRR: Coefficient of variation in electrocardiographic R-R interval variability; DPD: 3,3-diphosphono-1,2-propanodicarboxylic acid; ECG: Electrocardiography; ECV: Extracellular volume;

ECHO: Echocardiographic; ER: Emergency room; FLC: Free light chain; Gl: Gastrointestinal; HF: Heart failure; HFpEF: Heart failure with preserved ejection fraction; HMDP: Hydroxymethylene diphosphonate; IBS: Irritable bowel syndrome; IP: Inpatient admissions; LV: Left ventricle; LVWT: Left ventricular wall thickness; MR: Magnetic resonance; MRI: Magnetic resonance imaging; NT-proBNP: N-terminal probrain natriuretic peptide; OGD: Esophago-gastroduodenoscopy; OH: Orthostatic hypotension; OP: Outpatient services; PYP: Pyrophosphate; SF-36: 36-Item Short Form Health Survey; SNAP: Sensory nerve action potential; SPECT: Single-photon emission computerized tomography; TTR: Transthyretin
}

\section{Acknowledgments}

Funding support for these recommendations was received from GlaxoSmithKline, lonis, Pfizer, and Alnylam; these companies were not involved in writing this manuscript. Medical writing and editorial assistance was provided by ApotheCom (San Francisco, CA, USA)

\section{Authors' contributions}

MG, DA, YA, JMB, PNH, SB, TC, RLC, TD, SD, BMD, MF, JDG, MG, IL, AVK, FLR, $\mathrm{OBS}, \mathrm{MSM}, \mathrm{JNN}, \mathrm{CCQ}, \mathrm{CR}, \mathrm{RW}$, and GM substantially contributed to the conception and development of this manuscript. MG wrote the first draft of the manuscript. All authors substantively revised the manuscript for important intellectual content and gave approval for it to be submitted for publication.

\section{Funding}

This article was sponsored by the Amyloidosis Research Consortium. The funders had no role in the development of these recommendations; preparation, review or approval of the manuscript; or the decision to submit the manuscript for publication.

\section{Availability of data and materials}

All data generated and analyzed during this study are included in the cited published articles.

\section{Ethics approval and consent to participate}

Not applicable since patient medical information was not directly included in this study. All data analyzed during this study were generated from cited published articles.

\section{Consent for publication}

Not applicable.

\section{Competing interests}

MG reports personal fees from lonis/Akcea, Alnylam, Prothena, Celgene, Janssen, Spectrum, Annexon, Appellis, Amgen, Medscape, Physicians Education Resource, AbbVie (Data Safety Monitoring board), Research to Practice; speaker fees from Teva, Johnson and Johnson, Medscape, DAVA Oncology; advisory boards for Pharmacyclics and Proclara; royalties from Springer Publishing; and grant funding from Amyloidosis Foundation, International Waldenstrom Foundation, Spectrum, and the National Cancer Institute (SPORE MM SPORE 5P50 CA186781-04).

DA reports grants from Alnylam and Pfizer and personal fees from Prothena, GlaxoSmithKline, Alnylam, and Pfizer.

$Y A, J M B$, and PNH have nothing to disclose.

SB reports personal fees from Pfizer.

TC was paid per protocol for clinical trials from FoldRx, Pfizer, lonis, and Alnylam and received grants from FoldRx and Pfizer; received support from Pfizer, lonis, Biogen, and Alnylam to attend scientific meetings; and has presented on behalf of Pfizer, Alnylam, GlaxoSmithKline, Prothena, and Ionis/ Akcea and received honoraria.

RLC reports consulting fees from Prothena, Janssen, Amgen, Takeda, SanofiAventis, Unum, Caelum and reports grant/research support from Prothena, Janssen, Takeda, and Karyopharm.

TD reports grants from Pfizer and Alnylam Pharmaceuticals and reports personal fees from lonis Pharmaceuticals, Prothena Group, and GlaxoSmithKline.

SD reports personal fees from Pfizer, GE Healthcare, and Advanced Accelerator Applications.

BMD reports personal fees from Pfizer and Alnylam Pharmaceuticals. MF reports a grant from GlaxoSmithKline and reports personal fees from British Heart Foundation, Pfizer, Alnylam Pharmaceuticals, and Prothena. JDG participated in advisory boards for Alnylam Pharmaceuticals and GlaxoSmithKline.

MG reports grants from Eidos Therapeutics, Pfizer, Alnylam Pharmaceuticals, and Prothena.

IL has received honoraria from Akcea Therapeutics.

AVK reports personal fees from Akcea Therapeutics, Eidos Therapeutics, Pfizer, Alnylam Pharmaceuticals.

FLR reports grants from Pfizer and personal fees from Pfizer and Alnylam Pharmaceuticals. 
OBS received honoraria and travel and consultancy fees from lonis/Akcea, Alnylam, Prothena, and Intellia.

MSM reports grants from Pfizer and Alnylam Pharmaceuticals and reports personal fees from Akcea Therapeutics, Ionis Pharmaceuticals, Prothena Corp, Pfizer, Alnylam Pharmaceuticals, Eidos Therapeutics, and GlaxoSmithKline. JNN reports grants from Pfizer, Eidos Therapeutics, and Akcea Therapeutics and personal fees from Pfizer, Akcea Therapeutics, Alnylam Pharmaceuticals, and lonis Pharmaceuticals.

CCQ reports personal fees from Alnylam Pharmaceuticals.

$\mathrm{CR}$ reports grants from Pfizer and personal fees from Pfizer and Alnylam Pharmaceuticals.

RW reports grants from Pfizer and Eidos Therapeutics and reports personal fees from Alnylam Pharmaceuticals, Pfizer, and Eidos Therapeutics. GM has received honoraria from Janssen and Prothena; travel support from Prothena and Celgene; and consulting fees from Millennium, Pfizer, Janssen, Prothena, and lonis.

\section{Author details}

'Mayo Clinic, 200 First Street SW, Rochester, MN 55905, USA. ${ }^{2}$ Referral Center for FAP, Neurology Department, APHP, INSERM U 1195, Université Paris-Sud, Le Kremlin Bicêtre, France. ${ }^{3}$ Department of Neurology, Graduate School of Medical Sciences, Kumamoto University, Kumamoto, Japan. ${ }^{4}$ Ophthalmology Service, Hospital de Santo António, Porto, Portugal. ${ }^{5}$ Columbia University Medical Center, New York, NY, USA. ${ }^{6}$ Centro Hospitalar do Porto, Porto, Portugal. ${ }^{7}$ John C. Davis Myeloma and Amyloid Program, Tufts Medical Center, Boston, MA, USA. ${ }^{8}$ Department of Cardiology, Referral Center for Cardiac Amyloidosis, GRC Amyloid Research Institute, DHU A-TVB, APHP CHU Henri Mondor and Université Paris Est Créteil, Créteil, France. 'Brigham and Women's Hospital, Boston, MA, USA. ${ }^{10}$ University of Pennsylvania Perelman School of Medicine, Philadelphia, PA, USA. ${ }^{11}$ National Amyloidosis Centre, University College London, London, UK. ${ }^{12}$ Amyloidosis Research Consortium, Newton, MA, USA. ${ }^{13}$ University of Heidelberg, Heidelberg, Germany. ${ }^{14}$ Boston University School of Medicine, Boston Medical Center, Boston, MA, USA. ${ }^{15}$ Department of Public Health and Clinical Medicine, Umeå University, Umeå, Sweden. ${ }^{16}$ University of Utah Health, Salt Lake City, UT, USA.

${ }^{17}$ University of Bologna, Bologna, Italy. ${ }^{18}$ Stanford Amyloid Center, Stanford University School of Medicine, Stanford, California, USA. ${ }^{19}$ Amyloidosis Research and Treatment Center Foundation, IRCCS Policlinico San Matteo, San Matteo, Italy. ${ }^{20}$ Department of Molecular Medicine, University of Pavia, Pavia, Italy.

Received: 11 March 2020 Accepted: 25 August 2020

Published online: 23 September 2020

\section{References}

1. Conceicao I, Gonzalez-Duarte A, Obici L, Schmidt HH, Simoneau D, Ong ML, et al. "red-flag" symptom clusters in transthyretin familial amyloid polyneuropathy. J Peripher Nerv Syst. 2016:21(1):5-9.

2. Costa PP, Figueira AS, Bravo FR. Amyloid fibril protein related to prealbumin in familial amyloidotic polyneuropathy. Proc Natl Acad Sci U S A. 1978;75(9): 4499-503.

3. Saraiva MJ, Birken S, Costa PP, Goodman DS. Amyloid fibril protein in familial amyloidotic polyneuropathy, Portuguese type. Definition of molecular abnormality in transthyretin (prealbumin). J Clin Invest. 1984;74(1): 104-19.

4. Saraiva MJ. Transthyretin amyloidosis: a tale of weak interactions. FEBS Lett. 2001;498(2-3):201-3

5. Coelho T, Ericzon BG, Falk R, Grogen D. A Physician's guide to Transthyretin amyloidosis; 2008

6. Lim KH, Dasari AK, Hung I, Gan Z, Kelly JW, Wemmer DE. Structural changes associated with Transthyretin Misfolding and amyloid formation revealed by solution and solid-state NMR. Biochemistry. 2016;55(13):1941-4.

7. Benson MD, Buxbaum JN, Eisenberg DS, Merlini G, Saraiva MJM, Sekijima Y, et al. Amyloid nomenclature 2018: recommendations by the International Society of Amyloidosis (ISA) nomenclature committee. Amyloid. 2018;25(4):215-9.

8. Ruberg FL, Maurer MS, Judge DP, Zeldenrust S, Skinner M, Kim AY, et al. Prospective evaluation of the morbidity and mortality of wild-type and V122l mutant transthyretin amyloid cardiomyopathy: the Transthyretin Amyloidosis Cardiac Study (TRACS). Am Heart J. 2012;164(2):222-8.e1.

9. Connors LH, Sam F, Skinner M, Salinaro F, Sun F, Ruberg FL, et al. Heart failure resulting from age-related cardiac amyloid disease associated with wild-type Transthyretin: a prospective, Observational Cohort Study. Circulation. 2016;133(3):282-90

10. Sattianayagam PT, Hahn AF, Whelan CJ, Gibbs SD, Pinney JH, Stangou AJ, et al. Cardiac phenotype and clinical outcome of familial amyloid polyneuropathy associated with transthyretin alanine 60 variant. Eur Heart J. 2012:33(9):1120-7.

11. Koike H, Yasuda T, Nishi R, Ikeda S, Kawagashira Y, lijima M, et al. Systemic angiopathy and axonopathy in hereditary transthyretin amyloidosis with Ala97Gly (p. Ala117Gly) mutation: a post-mortem analysis. Amyloid. 2018; 25(2):141-2.

12. Swiecicki PL, Zhen DB, Mauermann ML, Kyle RA, Zeldenrust SR, Grogan M, et al. Hereditary ATTR amyloidosis: a single-institution experience with 266 patients. Amyloid. 2015;22(2):123-31.

13. Maurer MS, Hanna M, Grogan M, Dispenzieri A, Witteles R, Drachman B, et al. Genotype and phenotype of Transthyretin cardiac amyloidosis: THAOS (Transthyretin amyloid outcome survey). J Am Coll Cardiol. 2016;68(2):161-72..

14. Koike H, Tanaka F, Hashimoto R, Tomita M, Kawagashira Y, lijima M, et al. Natural history of transthyretin Val30Met familial amyloid polyneuropathy: analysis of late-onset cases from non-endemic areas. J Neurol Neurosurg Psychiatry. 2012;83(2):152-8.

15. Grogan M, Scott CG, Kyle RA, Zeldenrust SR, Gertz MA, Lin G, et al. Natural history of wild-type Transthyretin cardiac amyloidosis and risk stratification using a novel staging system. J Am Coll Cardiol. 2016;68(10):1014-20.

16. Ando Y, Coelho T, Berk JL, Cruz MW, Ericzon BG, Ikeda S, et al. Guideline of transthyretin-related hereditary amyloidosis for clinicians. Orphanet J Rare Dis. 2013;8:31.

17. Gertz MA. Hereditary ATTR amyloidosis: burden of illness and diagnostic challenges. Am J Manag Care. 2017;23(7 Suppl):S107-S12.

18. Coelho T, Maurer MS, Suhr OB. THAOS - the Transthyretin amyloidosis outcomes survey: initial report on clinical manifestations in patients with hereditary and wild-type transthyretin amyloidosis. Curr Med Res Opin. 2013;29(1):63-76.

19. Ruberg FL, Berk JL. Transthyretin (TTR) cardiac amyloidosis. Circulation. 2012; 126(10):1286-300.

20. Wixner J, Mundayat R, Karayal ON, Anan I, Karling P, Suhr OB, et al. THAOS: gastrointestinal manifestations of transthyretin amyloidosis - common complications of a rare disease. Orphanet J Rare Dis. 2014;9:61.

21. Gonzalez-Duarte A, Barroso F, Mundayat R, Shapiro B. Blood pressure and orthostatic hypotension as measures of autonomic dysfunction in patients from the transthyretin amyloidosis outcomes survey (THAOS). Auton Neurosci. 2019;222:102590

22. Sperry BW, Reyes BA, Ikram A, Donnelly JP, Phelan D, Jaber WA, et al. Tenosynovial and cardiac amyloidosis in patients undergoing carpal tunnel release. J Am Coll Cardiol. 2018;72(17):2040-50.

23. Westermark P, Westermark GT, Suhr OB, Berg S. Transthyretin-derived amyloidosis: probably a common cause of lumbar spinal stenosis. Ups J Med Sci. 2014;119(3):223-8.

24. Koike H, Hashimoto R, Tomita M, Kawagashira Y, lijima M, Tanaka F, et al. Diagnosis of sporadic transthyretin Val30Met familial amyloid polyneuropathy: a practical analysis. Amyloid. 2011;18(2):53-62.

25. Adams D, Lozeron P, Theaudin M, Mincheva Z, Cauquil C, Adam C, et al. Regional difference and similarity of familial amyloidosis with polyneuropathy in France. Amyloid. 2012;19(Suppl 1):61-4.

26. Nakagawa M, Sekijima Y, Yazaki M, Tojo K, Yoshinaga T, Doden T, et al. Carpal tunnel syndrome: a common initial symptom of systemic wild-type ATTR (ATTRwt) amyloidosis. Amyloid. 2016;23(1):58-63.

27. Donnelly JP, Hanna M, Sperry BW, Seitz WH J. Carpal Tunnel Syndrome: A Potential Early, Red-Flag Sign of Amyloidosis. J Hand Surg [Am]. 2019;44(10): 868-76.

28. Sueyoshi T, Ueda M, Jono H, Irie H, Sei A, Ide J, et al. Wild-type transthyretin-derived amyloidosis in various ligaments and tendons. Hum Pathol. 2011:42(9):1259-64

29. Maurer MS, Schwartz JH, Gundapaneni B, Elliott PM, Merlini G, WaddingtonCruz M, et al. Tafamidis treatment for patients with transthyretin amyloid cardiomyopathy. N Engl J Med. 2018;379(11):1007-16.

30. Benson MD, Waddington-Cruz M, Berk JL, Polydefkis M, Dyck PJ, Wang AK, et al. Inotersen treatment for patients with hereditary Transthyretin amyloidosis. N Engl J Med. 2018;379(1):22-31.

31. Adams D, Gonzalez-Duarte A, O'Riordan WD, Yang CC, Ueda M, Kristen AV, et al. Patisiran, an RNAi therapeutic, for hereditary Transthyretin amyloidosis. N Engl J Med. 2018;379(1):11-21. 
32. Tanskanen M, Peuralinna T, Polvikoski T, Notkola IL, Sulkava R, Hardy J, et al. Senile systemic amyloidosis affects $25 \%$ of the very aged and associates with genetic variation in alpha2-macroglobulin and tau: a population-based autopsy study. Ann Med. 2008:40(3):232-9.

33. Mohammed SF, Mirzoyev SA, Edwards WD, Dogan A, Grogan DR, Dunlay $\mathrm{SM}$, et al. Left ventricular amyloid deposition in patients with heart failure and preserved ejection fraction. JACC Heart Fail. 2014;2(2):113-22.

34. Gonzalez-Lopez E, Gallego-Delgado M, Guzzo-Merello G, de Haro-Del Moral FJ, Cobo-Marcos M, Robles C, et al. Wild-type transthyretin amyloidosis as a cause of heart failure with preserved ejection fraction. Eur Heart J. 2015; 36(38):2585-94.

35. Castano A, Narotsky DL, Hamid N, Khalique OK, Morgenstern R, DeLuca A, et al. Unveiling transthyretin cardiac amyloidosis and its predictors among elderly patients with severe aortic stenosis undergoing transcatheter aortic valve replacement. Eur Heart J. 2017:38(38):2879-87.

36. Jacobson DR, Pastore R, Pool S, Malendowicz S, Kane I, Shivji A, et al. Revised transthyretin lle 122 allele frequency in African-Americans. Hum Genet. 1996;98(2):236-8.

37. Yamashita T, Hamidi Asl K, Yazaki M, Benson MD. A prospective evaluation of the transthyretin Ile122 allele frequency in an African-American population. Amyloid. 2005;12(2):127-30.

38. Buxbaum JN, Ruberg FL. Transthyretin V122I (pV142l)* cardiac amyloidosis: an age-dependent autosomal dominant cardiomyopathy too common to be overlooked as a cause of significant heart disease in elderly African Americans. Genet Med. 2017;19(7):733-42.

39. Jacobson DR, Alexander AA, Tagoe C, Buxbaum JN. Prevalence of the amyloidogenic transthyretin (TTR) V122I allele in 14333 African-Americans. Amyloid. 2015;22(3):171-4.

40. Bureau UC. Quick Facts United States. Population estimates, July 1, 2018 (V2018). https://www.census.gov/quickfacts/fact/table/US/PST045218. Washington, DC: US Census Bureau; 2018.

41. Hawkins PN, Ando Y, Dispenzeri A, Gonzalez-Duarte A, Adams D, Suhr OB. Evolving landscape in the management of transthyretin amyloidosis. Ann Med. 2015;47(8):625-38.

42. Koike H, Sobue G. Late-onset familial amyloid polyneuropathy in Japan. Amyloid. 2012;19(Suppl 1):55-7

43. Schmidt HH, Waddington-Cruz M, Botteman MF, Carter JA, Chopra AS, Hopps $M$, et al. Estimating the global prevalence of transthyretin familial amyloid polyneuropathy. Muscle Nerve. 2018;57(5):829-37.

44. Gertz MA, Benson MD, Dyck PJ, Grogan M, Coelho T, Cruz M, et al. Diagnosis, prognosis, and therapy of Transthyretin amyloidosis. J Am Coll Cardiol. 2015;66(21):2451-66.

45. Adams D, Suhr OB, Hund E, Obici L, Tournev I, Campistol JM, et al. First European consensus for diagnosis, management, and treatment of transthyretin familial amyloid polyneuropathy. Curr Opin Neurol. 2016; 29(Suppl 1):S14-26.

46. Lousada I, Comenzo RL, Landau H, Guthrie S, Merlini G. Patient experience with hereditary and senile systemic amyloidoses: a survey from the Amyloidosis Research Consortium. Orphanet J Rare Dis. 2015;10(Suppl 1):P22 P.

47. Lane T, Fontana M, Martinez-Naharro A, Quarta CC, Whelan CJ, Petrie A, et al. Natural history, quality of life, and outcome in cardiac Transthyretin amyloidosis. Circulation. 2019;140(1):16-26.

48. Yanagisawa A, Ueda M, Sueyoshi T, Okada T, Fujimoto T, Ogi Y, et al. Amyloid deposits derived from transthyretin in the ligamentum flavum as related to lumbar spinal canal stenosis. Mod Pathol. 2015;28(2):201-7.

49. Obici L, Kuks JB, Buades J, Adams D, Suhr OB, Coelho T, et al. Recommendations for presymptomatic genetic testing and management of individuals at risk for hereditary transthyretin amyloidosis. Curr Opin Neurol. 2016;29(Suppl 1):S27-35

50. Yarlas A, Gertz MA, Dasgupta NR, Obici L, Pollock M, Ackermann EJ, et al. Burden of hereditary transthyretin amyloidosis on quality of life. Muscle Nerve. 2019:60:169-75.

51. Stewart M, Shaffer S, Murphy B, Loftus J, Alvir J, Cicchetti M, et al. Characterizing the high disease burden of Transthyretin amyloidosis for patients and caregivers. Neurol Ther. 2018;7(2):349-64.

52. Maurer MS, Elliott $P$, Comenzo R, Semigran M, Rapezzi C. Addressing common questions encountered in the diagnosis and Management of Cardiac Amyloidosis. Circulation. 2017;135(14):1357-77.

53. Maurer MS, Bokhari S, Damy T, Dorbala S, Drachman BM, Fontana M, et al. Expert consensus recommendations for the suspicion and diagnosis of Transthyretin cardiac amyloidosis. Circ Heart Fail. 2019;12(9):e006075.
54. Treibel TA, Fontana M, Gilbertson JA, Castelletti S, White SK, Scully PR, et al. Occult transthyretin cardiac amyloid in severe calcific aortic stenosis: prevalence and prognosis in patients undergoing surgical aortic valve replacement. Circ Cardiovasc Imaging. 2016;9e005066.

55. Castano A, Narotsky D, Kodali S, Nazif T, George I, Vahl T, et al. Transthyretin cardiac amyloidosis is prevalent among men with severe aortic stenosis undergoing transcatheter aortic valve replacement. J Am Coll Cardiol. 2016; 67(13 Supplement):1535.

56. Damy T, Costes B, Hagege AA, Donal E, Eicher JC, Slama M, et al. Prevalence and clinical phenotype of hereditary transthyretin amyloid cardiomyopathy in patients with increased left ventricular wall thickness. Eur Heart J. 2016; 37(23):1826-34.

57. Parato VM, Antoncecchi V, Sozzi F, Marazia S, Zito A, Maiello M, et al. Echocardiographic diagnosis of the different phenotypes of hypertrophic cardiomyopathy. Cardiovasc Ultrasound. 2016;14(1):30.

58. Rapezzi C, Lorenzini M, Longhi S, Milandri A, Gagliardi C, Bartolomei I, et al. Cardiac amyloidosis: the great pretender. Heart Fail Rev. 2015;20(2):117-24.

59. Gustavsson S, Granasen G, Gronlund C, Wiklund U, Morner S, Henein M, et al. Can echocardiography and ECG discriminate hereditary transthyretin V30M amyloidosis from hypertrophic cardiomyopathy? Amyloid. 2015;22(3):163-70.

60. Perugini E, Guidalotti PL, Salvi F, Cooke RM, Pettinato C, Riva L, et al. Noninvasive etiologic diagnosis of cardiac amyloidosis using 99mTc-3,3diphosphono-1,2-propanodicarboxylic acid scintigraphy. J Am Coll Cardiol. 2005;46(6):1076-84

61. Ando Y, Araki S, Shimoda O, Kano T. Role of autonomic nerve functions in patients with familial amyloidotic polyneuropathy as analyzed by laser Doppler flowmetry, capsule hydrograph, and cardiographic R-R interval. Muscle Nerve. 1992;15(4):507-12.

62. Masuda T, Ueda M, Kitajima M, Morita K, Misumi Y, Yamashita T, et al. Teaching Neurolmages: morphology of lumbosacral dorsal root ganglia and plexus in hereditary transthyretin amyloidosis. Neurology. 2018;91(19): e1834-e5.

63. Dorbala S, Ando Y, Bokhari S, Dispenzieri A, Falk RH, Ferrari VA, et al. ASNC/ AHA/ASE/EANM/HFSA/ISA/SCMR/SNMMI expert consensus recommendations for multimodality imaging in cardiac amyloidosis: part 1 of 2-evidence base and standardized methods of imaging. J Card Fail. 2019; 25(11):e1-e39.

64. Dorbala S, Ando Y, Bokhari S, Dispenzieri A, Falk RH, Ferrari VA, et al. ASNC/ AHA/ASE/EANM/HFSA/ISA/SCMR/SNMMI expert consensus recommendations for multimodality imaging in cardiac amyloidosis: part 2 of 2-diagnostic criteria and appropriate utilization. J Card Fail. 2019;25(11): 854-65.

65. Theaudin M, Lozeron P, Algalarrondo V, Lacroix C, Cauquil C, Labeyrie C, et al. Upper limb onset of hereditary transthyretin amyloidosis is common in non-endemic areas. Eur J Neurol. 2019;26(3):497-e36.

66. Mariani LL, Lozeron P, Theaudin M, Mincheva Z, Signate A, Ducot B, et al. Genotype-phenotype correlation and course of transthyretin familial amyloid polyneuropathies in France. Ann Neurol. 2015;78(6):901-16.

67. Carr AS, Pelayo-Negro AL, Evans MR, Laura M, Blake J, Stancanelli C, et al. A study of the neuropathy associated with transthyretin amyloidosis (ATTR) in the UK. J Neurol Neurosurg Psychiatry. 2016;87(6):620-7.

68. Adams D, Koike H, Slama M, Coelho T. Hereditary transthyretin amyloidosis: a model of medical progress for a fatal disease. Nat Rev Neurol. 2019;15(7): 387-404.

69. Lozeron P, Mariani LL, Dodet P, Beaudonnet G, Theaudin M, Adam C, et al. Transthyretin amyloid polyneuropathies mimicking a demyelinating polyneuropathy. Neurology. 2018;91(2):e143-e52.

70. Cortese A, Vegezzi E, Lozza A, Alfonsi E, Montini A, Moglia A, et al. Diagnostic challenges in hereditary transthyretin amyloidosis with polyneuropathy: avoiding misdiagnosis of a treatable hereditary neuropathy. J Neurol Neurosurg Psychiatry. 2017;88(5):457-8.

71. Tashima K, Suhr OB, Ando Y, Holmgren G, Yamashita T, Obayashi K, et al. Gastrointestinal dysfunction in familial amyloidotic polyneuropathy (ATTR Val30Met)--comparison of Swedish and Japanese patients. Amyloid. 1999; 6(2):124-9.

72. Steen LE, Oberg L. Familial amyloidosis with polyneuropathy: roentgenological and gastroscopic appearance of gastrointestinal involvement. Am J Gastroenterol. 1983:78(7):417-20.

73. Freudenthaler S, Hegenbart U, Schonland S, Behrens HM, Kruger S, Rocken C. Amyloid in biopsies of the gastrointestinal tract-a retrospective observational study on 542 patients. Virchows Arch. 2016;468(5):569-77. 
74. Yoshimatsu S, Ando Y, Terazaki H, Sakashita N, Tada S, Yamashita T, et al. Endoscopic and pathological manifestations of the gastrointestinal tract in familial amyloidotic polyneuropathy type I (Met30). J Intern Med. 1998; 243(1):65-72.

75. Wixner J, Karling P, Rydh A, Hornsten R, Wiklund U, Anan I, et al. Gastric emptying in hereditary transthyretin amyloidosis: the impact of autonomic neuropathy. Neurogastroenterol Motil. 2012;24(12):1111-e568.

76. Nativi-Nicolau J, Maurer MS. Amyloidosis cardiomyopathy: update in the diagnosis and treatment of the most common types. Curr Opin Cardiol. 2018;33(5):571-9.

77. Gillmore JD, Maurer MS, Falk RH, Merlini G, Damy T, Dispenzieri A, et al. Nonbiopsy diagnosis of cardiac Transthyretin amyloidosis. Circulation. 2016; 133(24):2404-12.

78. Falk RH, Quarta CC, Dorbala S. How to image cardiac amyloidosis. Circ Cardiovasc Imaging. 2014;7(3):552-62

79. Do Amaral B, Coelho T, Sousa A, Guimaraes A. Usefulness of labial salivary gland biopsy in familial amyloid polyneuropathy Portuguese type. Amyloid. 2009;16(4):232-8.

80. Fine NM, Arruda-Olson AM, Dispenzieri A, Zeldenrust SR, Gertz MA, Kyle RA, et al. Yield of noncardiac biopsy for the diagnosis of transthyretin cardiac amyloidosis. Am J Cardiol. 2014;113(10):1723-7.

81. England JD, Gronseth GS, Franklin G, Carter GT, Kinsella LJ, Cohen JA, et al. Evaluation of distal symmetric polyneuropathy: the role of laboratory and genetic testing (an evidence-based review). Muscle Nerve. 2009; 39(1):116-25.

82. Sekijima Y, Ueda M, Koike H, Misawa S, Ishii T, Ando Y. Diagnosis and management of transthyretin familial amyloid polyneuropathy in Japan: red-flag symptom clusters and treatment algorithm. Orphanet J Rare Dis. 2018;13(1):6.

83. Rowczenio DM, Noor I, Gillmore JD, Lachmann HJ, Whelan C, Hawkins PN, et al. Online registry for mutations in hereditary amyloidosis including nomenclature recommendations. Hum Mutat. 2014;35(9):E2403-E12.

84. Donnelly JP, Hanna M. Cardiac amyloidosis: an update on diagnosis and treatment. Cleve Clin J Med. 2017;84(12 Suppl 3):12-26.

85. Ikram A, Sperry B, Reyes B, Seitz W, Hanna M. Carpal Tunnel Syndrome and Amyloid Cardiomyopathy. In: 3021, editor. 21st Annual Scientific Meeting HFSA supplement; 2017.

86. Coelho T, Ericzon BG, Falk R, Grogan D, Ikeda SI, Maurer M, et al. A Physician's Guide to Transthyretin Amyloidosis. 2008.

87. Galat A, Guellich A, Bodez D, Slama M, Dijos M, Zeitoun DM, et al. Aortic stenosis and transthyretin cardiac amyloidosis: the chicken or the egg? Eur Heart J. 2016;37(47):3525-31.

\section{Publisher's Note}

Springer Nature remains neutral with regard to jurisdictional claims in published maps and institutional affiliations.

Ready to submit your research? Choose BMC and benefit from:

- fast, convenient online submission

- thorough peer review by experienced researchers in your field

- rapid publication on acceptance

- support for research data, including large and complex data types

- gold Open Access which fosters wider collaboration and increased citations

- maximum visibility for your research: over $100 \mathrm{M}$ website views per year

At $\mathrm{BMC}$, research is always in progress.

Learn more biomedcentral.com/submissions 